\title{
REQUISITOS DE INFORMAÇÃO E MAPAS DO PROCESSO DE PROJETO DE ESTRUTURAS EM CONCRETO ARMADO: UM ESTUDO DE CASO UTILIZANDO A METODOLOGIA IDM
}

\author{
INFORMATION REQUIREMENTS AND PROCESS MAPS FOR THE REINFORCED \\ CONCREIE STRUCTURES DESIGN: A CASE STUDY USING THE IDM \\ METHODOLOGY
}

\author{
Cristiano Eduardo Antunes
}

Sérgio Scheer

\begin{abstract}
The construction industry is facing the Building Information Modeling (BIM) paradigm and all its potential. In order to this paradigm becomes largely adopted and fully utilized, the interoperability issue must be properly addressed. While the IFC schema covers the data model necessary for data exchange, the processes occurring daily in the industry need to be better known. In this sense, this paper reports a research that explored the design process of reinforced concrete structures using BIM based systems. To reach this goal, a case study was developed in a structural design company, where the researcher collected data by participant observation, interviews and documental analysis. After the data collection and the analysis of the internal design routines and external communications during the design process, process maps were elaborated containing all the activities developed during the contracted projects. Furthermore, it was appropriately registered the information requirements for each one of the activities using the IDM (Information Delivery Manual) standards. It was possible to characterize the design process of reinforced concrete structures in the studied company when using BIM based systems, as well as to identify the stakeholder information requirements. After the processes and information flows analysis it was also possible to propose a new optimized workflow. This workflow aimed to reduce the number of analogic activities during the studied design process, as well as helped to propose new information exchanges following the IDM methodology.
\end{abstract}

Keywords: Building Information Modeling. BIM. Information Delivery Manual. Information requirements. Structural design process.

Cristiano Eduardo Antunes

Procalc Estruturas, Curitiba - PR,

Pontifícia Universidade Católica do Paraná, Escola Politécnica, Curitiba - PR, cristianoea@hotmail.com.

Sérgio Scheer

Universidade Federal do Paraná, Departamento de Construção Civil, Curitiba -PR, scheer@ufpr.br.

\section{Introdução}

A importância da indústria da construção na economia é considerável. Por sua importância, acaba por receber uma ampla pressão para redução de desperdícios e melhoria de seus processos. Nesse contexto, a atividade de projeto de qualquer empreendimento ressalta-se como fundamental para que essas desejadas melhorias de fato ocorram.

Posto isso, atualmente a indústria da AEC (Arquitetura, Engenharia e Construção) observa as vantagens que a Modelagem da Informação da Construção (BIM, sigla em inglês para Building Information Modeling) pode trazer. O BIM é conceituado por Eastman et al. (2008) como uma tecnologia de modelagem e um conjunto de processos associados que visam a produção, comunicação e análise de modelos de construção. Apresenta grande potencial para aprimoramento de numerosos aspectos do processo construtivo, incluindo a atividade projetual.

How to cite this article:

ANTUNES, Cristiano Eduardo; SCHEER, Sérgio. Requisitos de informação e mapas do processo de projeto de estruturas em concreto armado: um estudo de caso utilizando a metodologia IDM. PARC Pesquisa em Arquitetura e Construção, Campinas, v.5, n.1, p. 18-34, jan./jun. 2014. 
Segundo Eastman et al. (2008), dentre os principais benefícios do uso da tecnologia BIM, pode-se citar o aumento da performance e da qualidade da edificação, o aumento da colaboração a partir do uso de técnicas de projeto integrado, visualizações antecipadas e mais precisas do projeto, geração de desenhos 2D consistentes em qualquer estágio do projeto e descoberta de erros e omissões de projeto antes da construção.

Não obstante tal potencial e uma gama de benefícios constatados na literatura, a adoção de BIM tem se mostrado gradual. Diversas barreiras para a adoção de BIM são citadas, como o alto custo de software e hardware, a necessidade de treinamento de pessoal e, principalmente, a interoperabilidade (ANDRADE; RUSCHEL, 2009; AZHAR, 2011).

Segundo Eastman et al. (2008), a interoperabilidade é a capacidade de dois ou mais sistemas compartilharem dados. Esta é uma questão ainda não resolvida no contexto BIM.

A principal iniciativa para tratar o problema da falta de interoperabilidade é o Industry Foundation Classes (IFC). O IFC é um padrão aberto de dados que busca ser para o BIM o que o formato DXF (Drawing eXchange Format) foi para a metodologia CAD (Computer Aided Design) tradicional. O IFC constitui-se por um conjunto de classes de objetos organizado de forma hierárquica, representando os diferentes componentes, produtos, processos e agentes do ciclo de vida de uma edificação (FERREIRA, 2005). Isto é, ele procura mapear todas as informações que podem vir a existir sobre um empreendimento.

Todavia, não é toda a informação que é compartilhada entre os diversos profissionais da indústria, mas sim uma parcela dos dados em uma determinada fase do projeto. Para identificar quais informações são necessárias em cada atividade e em cada etapa de um empreendimento, a BuildingSMART (2010), responsável pelo desenvolvimento do padrão IFC, propôs o Information Delivery Manual (IDM).

O IDM procura mapear os processos que ocorrem dentro da atividade construtiva, a informação indispensável para que aconteçam e os resultados que geram. A BuildingSMART cita benefícios do IDM para usuários finais e para desenvolvedores. Para o usuário final o IDM oferece uma descrição compreensível dos processos que ocorrem na indústria, os resultados desses processos, os envolvidos, e as informações que cada um necessita. Para o desenvolvedor, o IDM especifica as capacidades IFC requeridas para suportar os processos, em termos de entidades, atributos, propriedades e property sets (BUILDINGSMART, 2010).
Posto isso, procurando o esclarecimento para o usuário final e também para desenvolvedores, o presente trabalho tem como objetivo principal explorar o processo de projeto de estruturas de concreto através de sistemas BIM, fazendo uso da metodologia IDM. Busca-se, especificamente, mapear o processo de projeto de estruturas de concreto através de sistemas BIM em um estudo de caso, identificar os requisitos de informação para que o processo aconteça corretamente e propor um novo processo que tire proveito das capacidades oferecidas pela Modelagem da Informação da Construção e pelo padrão IFC no tocante à interoperabilidade. Isto é, procurou-se propor um fluxo que reduzisse o número de tarefas analógicas e se baseasse em trocas de informações realizadas através do padrão IFC.

Os resultados da presente pesquisa são delimitados ao que foi analisado em um estudo de caso com observação participante realizado na cidade de Curitiba, estado do Paraná, no intervalo de tempo de julho de 2013 a janeiro de 2014. Tais resultados são válidos para projetos de estruturas em concreto armado; não foram feitas considerações tendo em vista qualquer outro tipo de projeto.

\section{Revisão bibliográfica}

\section{Modelagem da Informação da Construção (BIM)}

A ideia da utilização de computadores para o desenvolvimento de produtos é antiga, e a história do surgimento do conceito hoje conhecido como BIM pode ser apreciada em Eastman et al. (2008).

De acordo com a National Building Information Modeling Standard (NBIMS, 2007), BIM deve ser entendido em três níveis de abstração: como um produto, como uma ferramenta e como um processo. Como um produto, BIM diz respeito ao modelo da edificação, uma entrega do processo de projeto, criado a partir de aplicativos computacionais, que são as ferramentas BIM. Tais ferramentas têm a capacidade de criar, agregar e extrair informações dos modelos BIM. Por fim, como um processo, BIM faz alusão à nova forma de colaboração que deve existir entre os profissionais, para que as informações necessárias a cada um possam ser obtidas. Isto é, os processos existentes na indústria devem ser revistos para tirar proveito da Modelagem da Informação da Construção.

Como pode ser observado na literatura técnica, diversos benefícios advêm da utilização de BIM, citando-se entre eles o aumento da qualidade das edificações, maior confiabilidade na documentação do projeto (desenhos), maior agilidade na extração de quantitativos e confecção de orçamentos, compatibilização espacial dos modelos 
Requisitos de informação e mapas do processo de projeto de estruturas em concreto armado: um estudo de caso utilizando a metodologia IDM

das várias especialidades, entre outros (EASTMAN et al., 2008; AZHAR, 2011).

Não obstante os diversos benefícios ressaltados, existem ainda barreiras que devem ser transpostas para que a Modelagem da Informação da Construção seja largamente adotada. A principal barreira observada é a falta de interoperabilidade.

Segundo Eastman et al. (2008), a interoperabilidade é a capacidade de intercâmbio e operação de informações entre dois ou mais sistemas. Para os autores, a interoperabilidade elimina a necessidade de reinserção manual de dados já introduzidos em um projeto, além de proporcionar fluxo eficiente entre as diversas tarefas que compõem um processo construtivo.

Em plataformas CAD tradicionais, o principal empreendimento que visava a interoperabilidade era o formato de dados Drawing eXchange Format (DXF). Em se tratando da Modelagem da Informação da Construção, a principal iniciativa é o padrão de dados Industry Foundation Classes (IFC).

\section{Industry Foundation Classes (IFC)}

A origem do IFC remete ao desenvolvimento do padrão Standard for the Exchange of Product model data (STEP), que tinha em vista a interoperabilidade de dados entre diversas indústrias, inclusive a da construção civil. Todavia, percebeu-se a necessidade da existência de um padrão de dados específico para a indústria da AEC, devido à alta complexidade desta.

Desta forma, no ano de 1994, doze empresas americanas formaram uma aliança chamada Industry Alliance for Interoperability (IAI) com o objetivo de desenvolver um padrão aberto de dados para dar suporte à Modelagem da Informação da Construção. Entre as vantagens de um padrão aberto de dados ressalta-se a não necessidade de tradutores diretos (normalmente de tecnologia proprietária, imersos em interesses comerciais) entre aplicativos, e todos os riscos que deles decorrem (LAAKSO; KIVINIEMI, 2012).

Desde então, diversas empresas se filiaram à IAI (atualmente conhecida como BuildingSMART) e foram lançadas várias versões do padrão IFC. A cada versão, ampliava-se o escopo de informações que o padrão abrangia e corrigiam-se possíveis problemas de versões anteriores. A versão mais recente do padrão é o IFC4. (LAAKSO; KIVINIEMI, 2012).

Do ponto de vista técnico, o IFC é um padrão aberto de dados, apoiado nos paradigmas da orientação a objetos. Ele é constituído por um apanhado de classes de objetos organizado de forma hierárquica, representando os diferentes componentes, produtos, processos e agentes do ciclo de vida de uma edificação (FERREIRA, 2005).

\section{Information Delivery Manual (IDM)}

O uso generalizado de BIM só irá acontecer quando, com efeito, as questões relacionadas à interoperabilidade (comunicação, troca e compartilhamento de dados) forem resolvidas. É imperativo que as informações que um profissional necessita para exercer suas tarefas estejam para ele disponíveis com a qualidade requerida e no tempo certo. Para que isso se dê, o fluxo de atividades e as informações que são criadas e consumidas durante o mesmo devem ser adequadamente conhecidas (BUILDINGSMART, 2010).

O padrão IFC propõe uma referência à totalidade das informações do ciclo de vida de uma edificação. Isso seria proveitoso caso fosse necessário intercambiar todas as informações de um projeto, o que não ocorre de fato. Na realidade, as informações que são compartilhadas são referentes a determinadas disciplinas, em uma alguma fase do projeto. Ou seja, apenas uma parte do IFC precisa ser utilizada em consecutivos momentos de troca de informação no fluxo do processo de projeto. Atinando a isso, a BuildingSMART propôs o Information Delivery Manual (IDM). O IDM visa proporcionar uma referência integrada, uma ligação entre processos e informação no contexto BIM. Ele busca identificar os processos que ocorrem dentro da atividade construtiva, a informação indispensável para que aconteçam e os resultados que geram (BUILDINGSMART, 2010).

De acordo com Berard e Karlshoj (2012), o IDM é uma linguagem de modelagem de processos de negócio que pretende suprir as deficiências de outras linguagens semelhantes. O IDM é tanto um produto como uma metodologia. Como produto, ele descreve os elementos de informação e seu intercâmbio através de modelos orientados a objetos. Como uma metodologia, explicita um processo colaborativo de reengenharia que envolve múltiplas competências (BERARD; KARLSHOJ, 2012).

Sob o aspecto de produto, o IDM possui diversos componentes que interagem entre si. Para Eastman et al. (2010) as partes fundamentais são o mapa de processos, os Modelos de Troca (exchange models) e os Objetos de Troca (exchange objects).

O mapa de processos descreve o fluxo de atividades dentro do limite de um determinado tópico, buscando entender como o trabalho é empreendido, quem são os atores envolvidos e quais são as informações necessárias, consumidas e produzidas para se atingir um objetivo bem definido (BUILDINGSMART, 2010). Ele procura compreender a sequência lógica de determinadas atividades e identificar os Modelos de Troca que dão 
Requisitos de informação e mapas do processo de projeto de estruturas em concreto armado: um estudo de caso utilizando a metodologia IDM

suporte a tais atividades. A BuildingSMART (2010) recomenda a utilização da linguagem BPMN (Business Process Modeling Notation) para a confecção dos mapas de processos.

O Modelo de Troca para Eastman et al. (2010) é equivalente ao que a BuildingSMART (2010) denomina de Requisito de Troca. Ele consiste no conjunto de informações que precisa ser compartilhado entre profissionais ou entre atividades para dar suporte a um determinado processo, possibilitando que mais tarefas sejam realizadas na sequência.

O Objeto de Troca é correspondente às Partes Funcionais citadas pela BuildingSMART (2010). Basicamente, os Objetos de Troca compõem os Modelos de Troca, e representam cada uma das informações que precisa ser compartilhada. Estas informações podem ainda estar acompanhadas da entidade IFC que lhes dão suporte.

Um mapa de processos possui diversas atividades e pode ser dotado por um ou mais modelos de troca. Cada modelo de troca é constituído por um ou mais objetos de troca.

Nos últimos anos, diversos estudos relevantes foram desenvolvidos tendo o IDM como tópico. Sacks et al. (2010) desenvolveram um IDM direcionado a estruturas de concreto pré-moldado. Mondrup, Karlshoj e Vestergaard (2012) analisaram a utilização de IDMs para facilitar a análise energética de edificações. Berard e Karlshoj (2012) estudaram o uso de IDMs para integrar a informação de componentes BIM. Aram, Eastman e Sacks (2013) desenvolveram um IDM da cadeia de suprimentos das armaduras para concreto. Estudos como o de Nawari (2012) também merecem destaque e ressaltam a importância do assunto no contexto atual de BIM.

\section{Método}

O método empregado para a presente pesquisa foi o estudo de caso. Desenvolveu-se um estudo de caso em uma empresa que atua na área de projetos de estruturas em concreto e faz uso de aplicativos BIM para tanto.

Na empresa, foram observados diversos projetos ao longo de aproximadamente 6 meses. É importante ressaltar que existiram pequenas variações entre os projetos, sendo que os resultados aqui relatados constituem-se em um retrato de um projeto típico.

A pesquisa foi dividida em diversas etapas, como pode ser avaliado na Figura 1. A primeira etapa constituiu-se de uma revisão bibliográfica exploratória, visando a ambientação no assunto e ainda dar ulterior suporte à definição do objetivo e do método de pesquisa.
Em seguida, elaborou-se uma revisão bibliográfica principal, que se reflete na seção anterior do presente trabalho.

Posteriormente o protocolo de coleta de dados foi confeccionado. Este visou orientar a execução do estudo de caso, guiando os procedimentos de campo (acesso à organização, coleta de dados relevantes, tópicos a nortearem a entrevista) e planejando o produto final da pesquisa (relatório do estudo, mapas de processos, entre outros). Finda esta etapa, foi efetivamente feito o contato com a empresa tendo em vista a autorização para o desenvolvimento do estudo.

Após tal contato, foi empreendida a coleta dos dados através de três fontes de evidências, quais sejam: observação participante, entrevistas e análise documental.

A observação participante, de acordo com Yin (2001, p. 116), é "uma modalidade especial de observação", na qual o pesquisador não tem apenas papel passivo. Ele "pode assumir uma variedade de funções dentro de um estudo de caso e pode, de fato, participar dos eventos que estão sendo estudados”. Assim, ocorreu o envolvimento direto nos acontecimentos do presente estudo, atuando-se no processo de projeto.

As entrevistas do estudo foram do tipo informais (uma classe de entrevistas não-estruturadas), aplicadas aos engenheiros e projetistas envolvidos no processo. A entrevista informal pode acontecer sempre que surge uma oportunidade para conversa sobre um tópico de interesse no local da pesquisa. Normalmente, esta oportunidade nasce após um período de observação, e o investigador busca entendimento sobre algo que aconteceu. Através de entrevistas informais, pode-se obter opiniões espontâneas e naturais dos envolvidos em uma determinada situação (ROBSON, 2002). Os tópicos que dirigiram as entrevistas informais foram o processo de projeto de estruturas, as tarefas exercidas por cada profissional, que informações este necessitava para desempenhar suas tarefas, que aplicativos utilizava, o sequenciamento entre as tarefas dos diferentes envolvidos, possíveis melhorias que poderiam ser implantadas, entre outros.

A análise documental buscou reforçar os dados coletados através das demais fontes de evidências. Os documentos analisados na presente pesquisa foram principalmente desenhos técnicos, memórias de cálculo e relatórios de sondagem.

Com a conclusão da coleta de dados, iniciou-se a etapa de confecção do relatório do estudo de caso. Na sequência, este relatório foi avaliado pelo diretor da empresa alvo do estudo de caso, procurando conferir maior confiabilidade aos dados coletados. 
A etapa de análise dos dados englobou a abstração do relatório do estudo de caso em mapas de processos e em Modelos de Troca. Ainda, avaliou-se qualitativamente os dados observados e propôs-se um novo processo de projeto.

Por fim, foram tecidas as conclusões da pesquisa.

Figura 1. Etapas da pesquisa

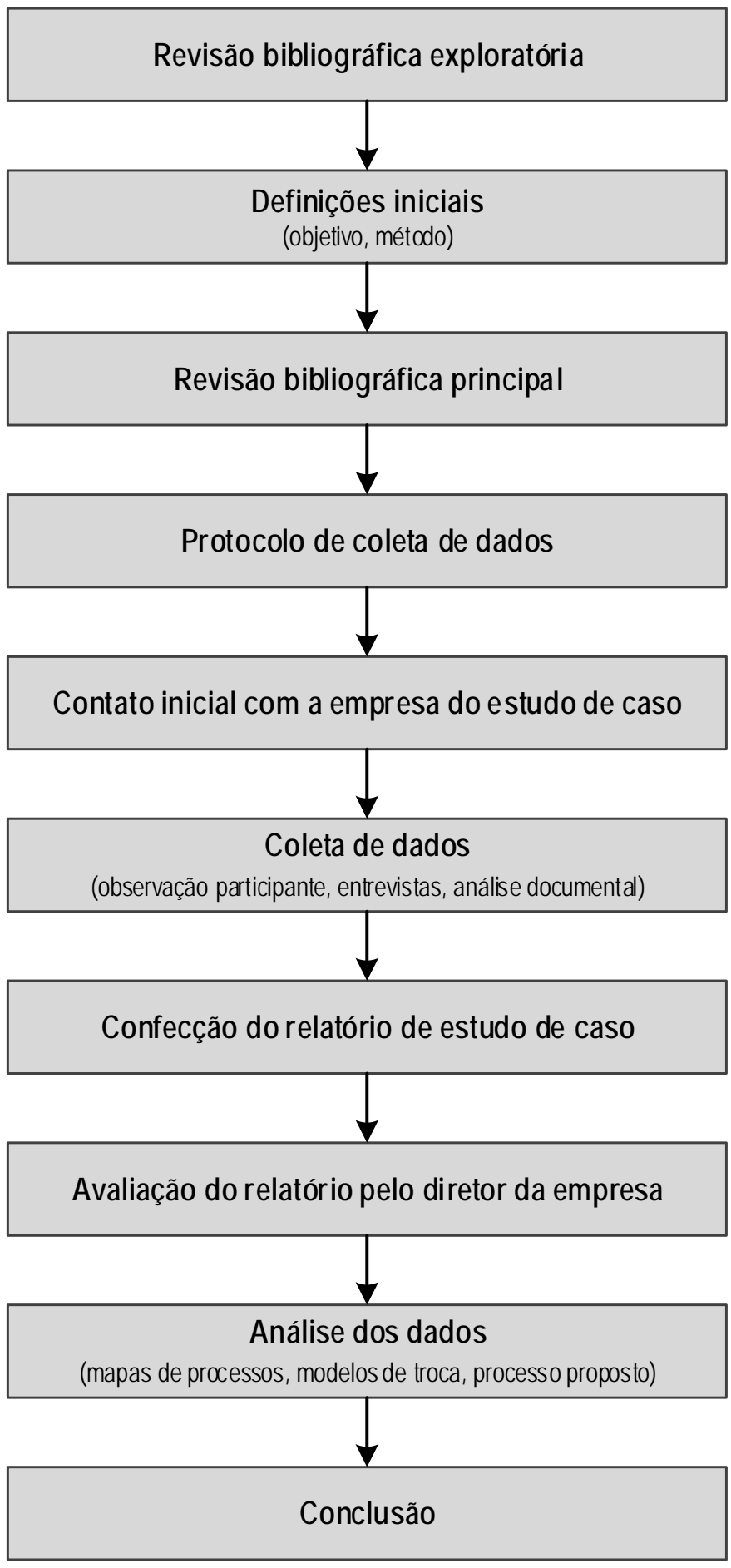

Fonte: Os autores

\section{Estudo de caso}

\section{A empresa do estudo}

A empresa alvo da presente pesquisa se localiza em Curitiba, estado do Paraná. Tem aproximadamente 25 anos de existência e conta com 18 funcionários. Destes, oito são engenheiros civis, incluindo dois diretores, oito são projetistas e dois auxiliam na administração do escritório. Na Figura 2 pode-se observar o organograma do corpo técnico da empresa.

Figura 2. Organograma da empresa
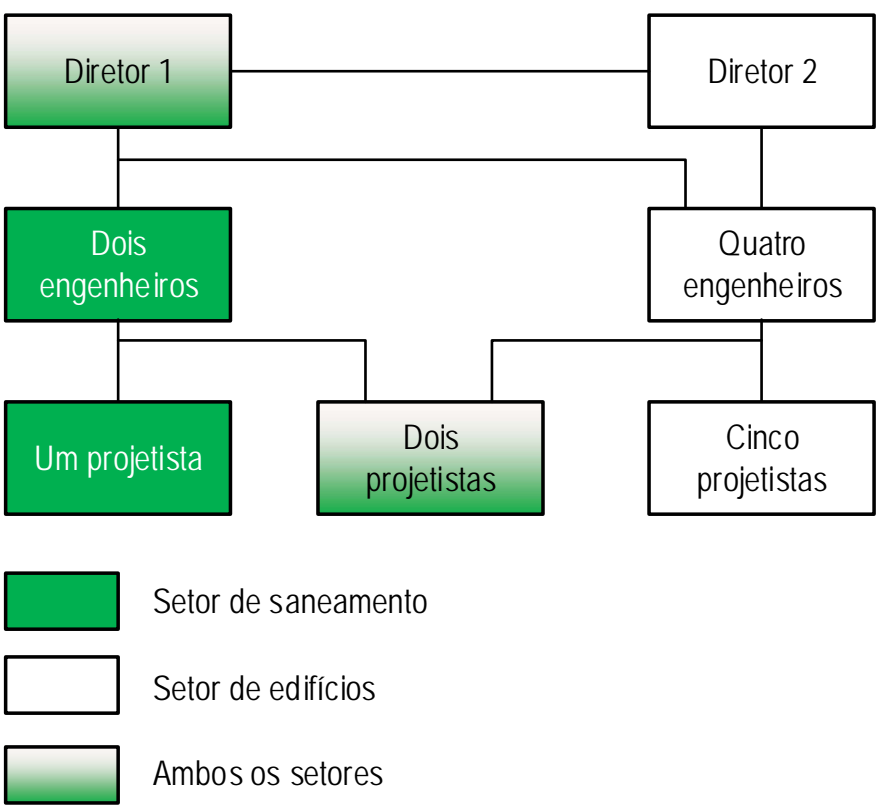

Setor de saneamento

Setor de edifícios

Ambos os setores

Fonte: Adaptada de Antunes (2014, p. 88)

A organização é especializada em projetos de estruturas em concreto armado e protendido. Os projetos desenvolvidos são de edificações residenciais, comerciais, industriais e obras de saneamento. Efetivamente, dois grandes setores podem ser apontados na empresa: projetos de estruturas de edifícios e projetos de estruturas para obras de saneamento. Estes serão de agora em diante denominados setor de edifícios e setor de saneamento, respectivamente.

O setor de edifícios detém a maior parte dos funcionários. Nele atuam seis engenheiros civis, incluindo os dois diretores, e sete projetistas. O setor de saneamento conta com dois engenheiros civis em tempo integral, além da dedicação parcial de um dos diretores e de dois projetistas. Em dedicação exclusiva a este setor existe um projetista.

Observou-se na empresa o considerável investimento em software e hardware. O setor de edifícios utiliza extensivamente o aplicativo CAD/TQS 17 para o cálculo 
e detalhamento das estruturas. Além do sistema CAD/TQS, os projetistas fazem uso do programa CAD/AGC\&DP, focado na criação de desenhos de armaduras. $\mathrm{O}$ setor de saneamento utiliza fundamentalmente dois aplicativos: o Scia Engineer 2013 e o Allplan Engineering 2013. Em segundo plano, é utilizado também, com menor frequência, o sistema CAD/AGC\&DP para a geração de alguns desenhos, como será explicitado no decorrer deste trabalho.

Como o objetivo da presente pesquisa foi explorar o processo de projeto de estruturas de concreto armado através de sistemas BIM, o setor de saneamento, que faz extensivo uso desta sorte de aplicativos, foi observado quando do estudo de caso.

\section{Projetos do setor de saneamento}

Os projetos estruturais do setor de saneamento visam atender Sistemas de Abastecimento de Água (SAA) e Sistemas de Esgotamento Sanitário (SES). As principais estruturas que compõem esses sistemas são reservatórios, filtros, desarenadores, floculadores, decantadores, estações elevatórias, entre outras. Exemplos dessas estruturas já modeladas no aplicativo Allplan Engineering podem ser visualizados na Figura 3.

Figura 3. Exemplos de estruturas para obras de saneamento



Filtro biológico

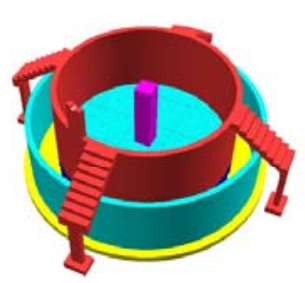

Filtro biológico
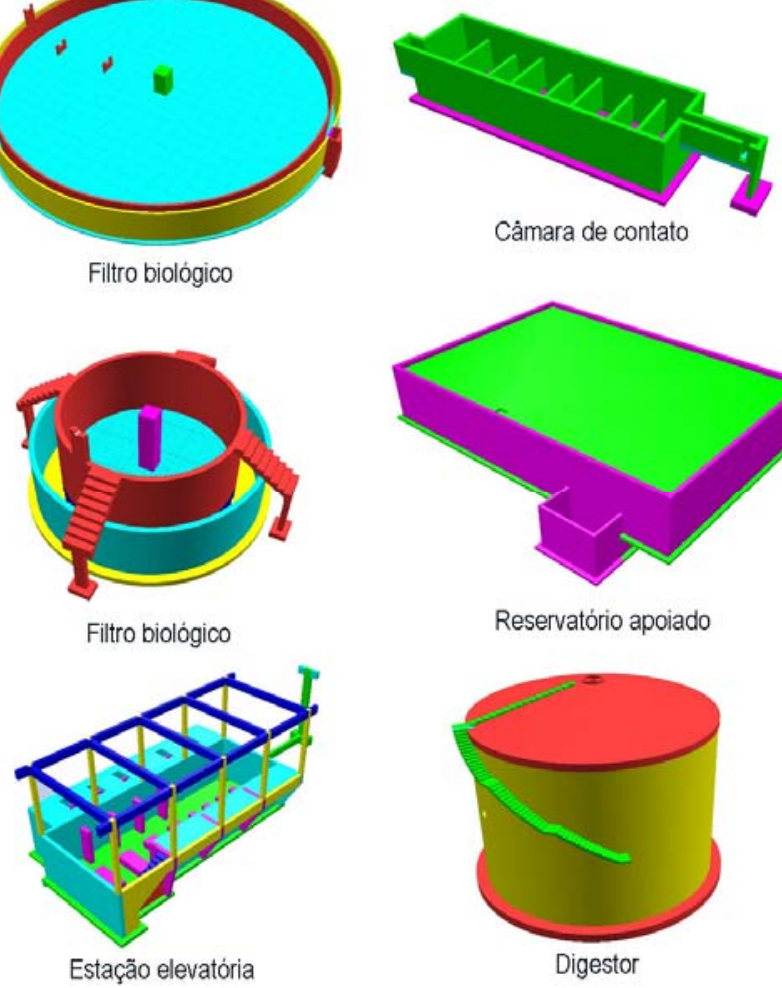

Càmara de contato

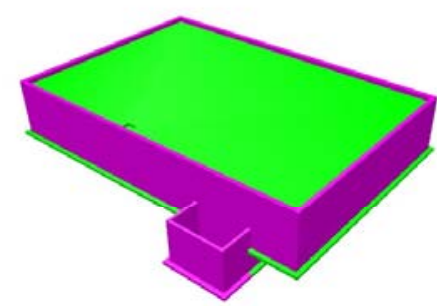

Reservatório apoiado



Fonte: Adaptada de Antunes (2014, p. 92)
O principal cliente dos projetos é a Companhia de Saneamento do Paraná (Sanepar). A Sanepar, criada no ano de 1963, é responsável pelo abastecimento de água, coleta de esgoto e gerenciamento de resíduos sólidos no estado do Paraná (SANEPAR, 2014). O regime de contratação dos projetos da Sanepar é a licitação.

O projeto de estruturas deve partir de um projeto básico de engenharia. Além do projeto básico, outro procedimento muito importante que deve ser realizado para dar suporte ao projeto estrutural é a investigação do solo. Para os projetos do setor de saneamento a investigação do subsolo é, via de regra, feita através da sondagem a percussão com SPT.

\section{Processo de projeto de estruturas para obras de saneamento}

Nesta seção será descrito o processo de projeto de estruturas para obras de saneamento observado na empresa. É importante ressaltar que os dados aqui apresentados e utilizados na prática pela empresa (carregamentos, resistências, coeficientes, pesos específicos, cobrimentos, entre outros) baseiam-se nas recomendações da NBR 6118:2007 (ABNT, 2007), nas prescrições para obras de saneamento da Sanepar e na experiência dos membros da organização.

Após definido o resultado da licitação para o projeto executivo, a contratante realiza uma reunião com a empresa que desenvolverá o projeto estrutural. O representante da empresa na reunião é o Diretor que atua parcialmente no setor de saneamento. Neste encontro, são discutidos os principais tópicos relacionados ao projeto em questão. Ainda, sempre que a obra possuir uma estrutura já projetada para algum outro empreendimento, esta é identificada. Tais estruturas são ditas repetidas.

Normalmente, são entregues ao Diretor, em formato físico e em formato digital, as pranchas com os desenhos do projeto básico de engenharia e os documentos relacionados à investigação do solo. É oportuno o comentário de que os projetos básicos de engenharia recebidos são totalmente desenvolvidos em plataforma CAD 2D. Já na empresa, os desenhos do projeto básico e demais documentos obtidos na reunião inicial são armazenados em um servidor.

Neste ponto, o Diretor faz uma avaliação dos desenhos do projeto básico e um pré-lançamento dos elementos estruturais. Na cópia física destes desenhos são feitas anotações que precisam ser observadas no cálculo e detalhamento das estruturas. Tais anotações dizem respeito às espessuras de elementos como paredes e lajes, seções transversais de vigas e pilares, armaduras para componentes de concreto calculadas manualmente, tipo de fundação, entre outros. Estruturas de porte reduzido, 
Requisitos de informação e mapas do processo de projeto de estruturas em concreto armado: um estudo de caso utilizando a metodologia IDM

que prescindem de cálculos estruturais complexos, podem ter também suas armaduras detalhadas nessa fase.

Na sequência, é feita a divisão dos trabalhos entre os colaboradores do setor. Os desenhos do projeto básico das estruturas de pequeno porte, que já tem seu prédimensionamento e sua definição de armaduras, são encaminhados diretamente aos projetistas para a geração dos projetos de forma e armadura, processo que será explorado na sequência. As estruturas de médio e grande porte que não são repetidas devem ser encaminhadas aos engenheiros do setor para o dimensionamento estrutural.

O dimensionamento é primordialmente realizado através do aplicativo Scia Engineer. Os engenheiros, de posse dos desenhos do projeto básico e do relatório de investigação do solo, procedem à criação do modelo BIM estrutural no software. Ressalta-se que é criado um modelo para cada estrutura, e não um modelo único para todo o empreendimento.

Após a criação dos vários componentes que fazem parte da estrutura, parte-se para a determinação dos parâmetros dos apoios da estrutura. Quando o tipo de fundação é o superficial determina-se o coeficiente de mola do solo e o mesmo é aplicado ao modelo.

Inicia-se, em seguida, o processo de criação das cargas que irão atuar na estrutura. Com as cargas aplicadas no modelo, criam-se também as combinações de cálculo, de forma que as cargas sejam arranjadas gerando as maiores solicitações possíveis nos vários elementos que constituem a estrutura. A título representativo, apresentase na Figura 4 o modelo de cálculo de um reator anaeróbio desenvolvido no Scia Engineer durante o estudo. $\mathrm{O}$ mesmo possui cerca de 7,0 m de altura (abaixo do solo) e 15,0 m de diâmetro.

Figura 4. Exemplo de modelo de cálculo

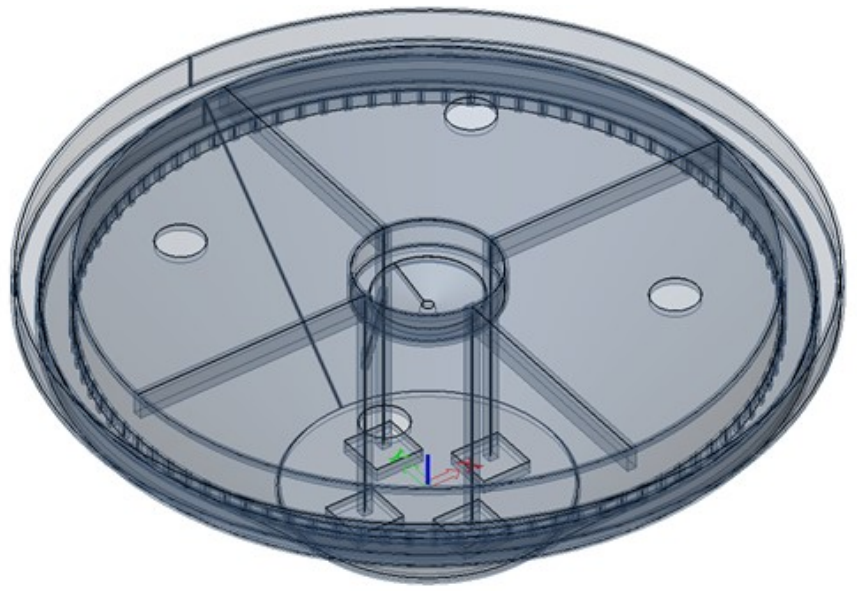

Fonte: Adaptada de Antunes (2014, p. 100)
A primeira verificação feita após o processamento da estrutura é a da tensão no solo de fundação. Avalia-se se as tensões atuantes são condizentes com a resistência do solo no local.

Em seguida, avaliam-se os deslocamentos dos elementos estruturais. Os deslocamentos obtidos em estruturas para obras de saneamento devem respeitar os limites estabelecidos pela NBR 6118:2007 (ABNT, 2007).

Na sequência, efetua-se, através do aplicativo, o dimensionamento da armadura de cada elemento. Entretanto, como o Scia Engineer, até o momento da escrita deste trabalho, não apresenta suporte às normas brasileiras, este dimensionamento é feito de acordo com normas estrangeiras. Logo, é necessária a verificação dos valores obtidos para as armaduras com o auxílio de planilhas de cálculo do Excel, que desempenham os dimensionamentos segundo às normas brasileiras.

A próxima etapa do processo é a geração dos relatórios de cálculo. Os relatórios gerados são os de Dados da Estrutura, Tensões no Solo, e resultados de esforços e armaduras em Paredes, Lajes, Vigas e Pilares. O Scia Engineer possui uma ferramenta que liga o modelo estrutural com os relatórios propriamente ditos. Assim, sempre que ocorrer uma mudança no modelo, todos os relatórios podem ser automaticamente atualizados, levando em consideração esta alteração. As planilhas de cálculo externas, entretanto, não são atualizadas, devendo o engenheiro fazer as mudanças devidas.

Posteriormente, prossegue-se ao detalhamento das estruturas por parte dos engenheiros. Nesta etapa, com base nos relatórios de cálculo, os engenheiros decidem os diâmetros, espaçamentos e formatos das barras de aço, além de explicitar as espessuras, seções transversais e alturas de elementos estruturais. Todas essas informações são, via de regra, representadas em forma de desenhos feitos manualmente sobre as pranchas do projeto básico.

Após o detalhamento da estrutura, pode-se seguir à etapa de geração dos desenhos de forma e armadura. Percebeuse, no estudo de caso, que esta fase pode ser desenvolvida de três maneiras distintas. Tais maneiras serão doravante denominadas de Fluxo A, Fluxo B e Fluxo C. As principais diferenças existentes entre estas variantes são o responsável pelos desenhos (engenheiro ou projetista) e a plataforma em que eles são desenvolvidos (BIM, através do Allplan, ou CAD 2D, através do CAD/AGC\&DP). Cada um dos fluxos encontra-se representado nas Figuras 9, 10 e 11, respectivamente, apresentadas na sequência. É detalhado neste trabalho apenas o Fluxo B.

No Fluxo B, os desenhos de detalhamento feitos pelos engenheiros são encaminhados ao projetista que trabalha exclusivamente no setor de saneamento. Neste fluxo, utiliza-se o aplicativo Allplan. Com base nos desenhos do 
ANTUNES, Cristiano Eduardo; SCHEER, Sergio

Requisitos de informação e mapas do processo de projeto de estruturas em concreto armado: um estudo de caso utilizando a metodologia IDM

projeto básico e no detalhamento feito pelos engenheiros, desenvolve-se um modelo BIM que irá servir aos propósitos de geração dos desenhos de forma e armadura. Tal modelo BIM é criado a partir das ferramentas de modelagem geométrica 3D do Allplan. A confecção dos desenhos de forma é feita a partir de cortes e plantas feitos neste modelo BIM. Nas figuras 5 e 6 são apresentados o modelo de uma estrutura e parte de seu desenho de formas.

Figura 5. Exemplo de modelo BIM

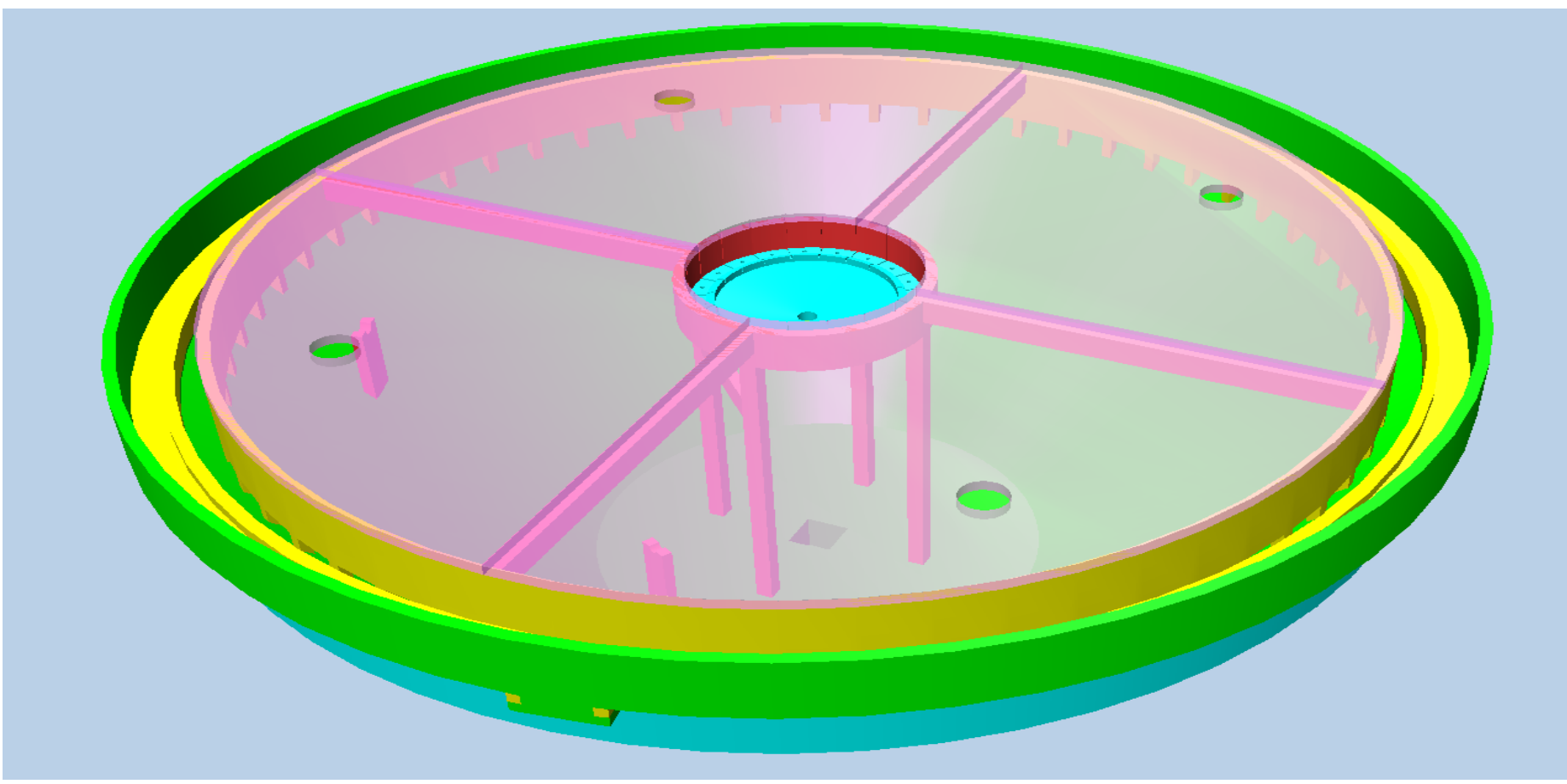

Fonte: Adaptada de Antunes (2014, p. 106)

Figura 6. Exemplo de parte de desenho de forma

CORTE A

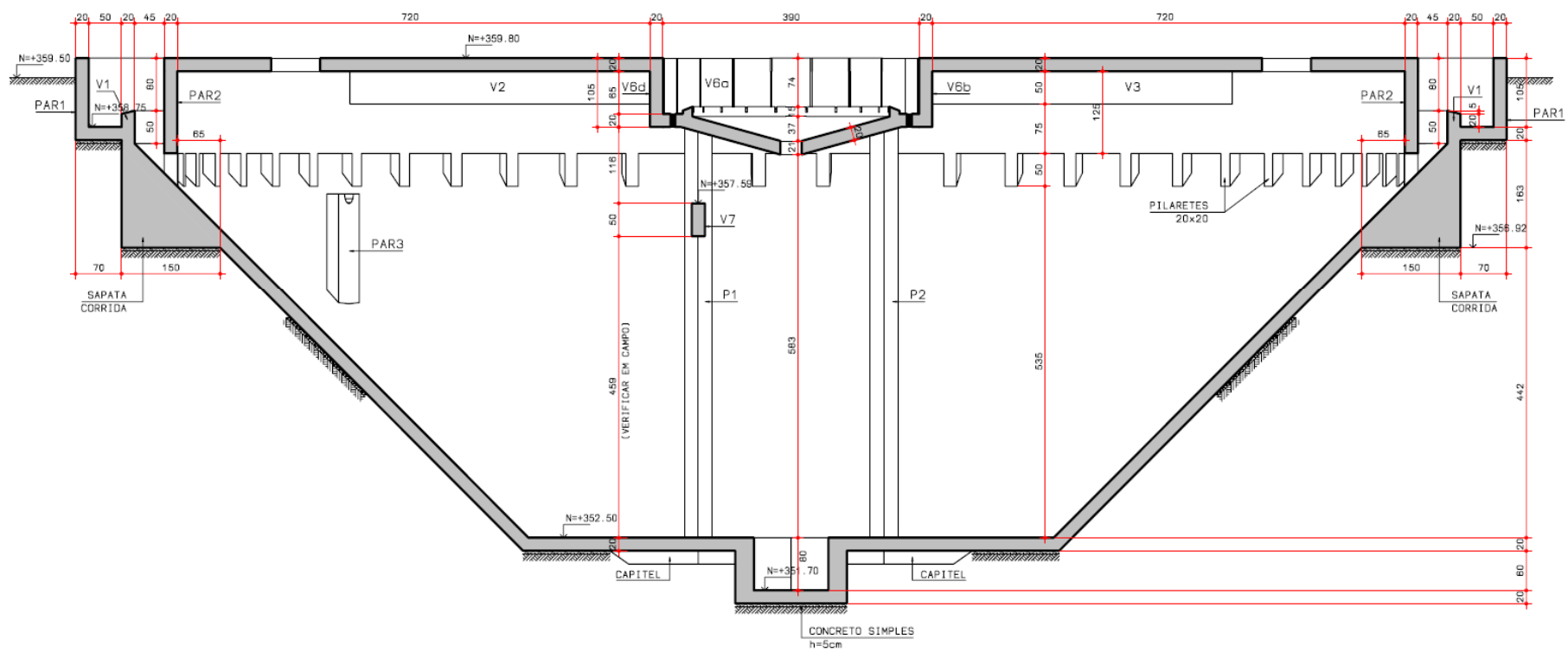

Fonte: Adaptada de Antunes (2014, p. 106) 
Na sequência, prossegue-se à modelagem das armaduras. Através da ferramenta apropriada para cada tipo de armadura (estribos, barras retas, barras circulares, barras variáveis, entre outros), as barras são desenhadas e distribuídas em cortes e, automaticamente, criadas no modelo 3D. Na Figura 7 podem ser observados exemplos da modelagem das armaduras. Quando todas as armaduras encontram-se plenamente modeladas, resta ainda a etapa de desenvolvimento dos desenhos. Nestes desenhos, deve-se estar presente o número de chamada, a quantidade, espaçamento, diâmetro e uma representação esquemática de cada barra. Nesta representação consta o comprimento de cada trecho da barra. Um exemplo de parte de um desenho de armadura encontra-se na Figura 8.

Tanto para o Fluxo B quanto para o Fluxo C, é importante assinalar que é criado um modelo para cada estrutura, e não um modelo único para todo o empreendimento.

Quando os desenhos de forma e armadura encontram-se finalizados, os mesmos devem ser verificados. No caso dos fluxos A e B, a verificação é feita por um dos engenheiros do setor. No caso do Fluxo C, o processo de verificação recai sobre o Diretor. Se os desenhos não forem aprovados na verificação, os mesmos retornam a quem os desenvolveu para que as alterações pertinentes sejam realizadas.

Se os desenhos forem aprovados na verificação, a etapa que dá sequência ao processo é o envio dos projetos à Sanepar. Além dos desenhos, é preciso encaminhar um documento com os resumos de volume de concreto, área de formas e armaduras. Este documento é constituído por uma planilha, desenvolvida pela auxiliar do escritório, através dos dados que constam nas próprias pranchas do projeto.

\section{Análise dos resultados}

Esta seção busca analisar e dispor os dados que foram coletados durante o desenvolvimento do estudo de caso. Expõe-se os mapas de processos criados para representar os Fluxos A, B e C, e um exemplo de Modelo de Troca. Os mapas de processos foram confeccionados na linguagem BPMN. Diferenciaram-se neles tarefas realizadas digitalmente e analogicamente (manuais).

\section{Fluxo A}

No Fluxo A, os desenhos de forma e armadura são desenvolvidos por um dos projetistas em dedicação parcial ao setor, através de ferramentas CAD 2D. O mapa de processos desenvolvido é exposto na Figura 9.

\section{Fluxo B}

O Fluxo B se diferencia dos demais devido ao método de desenvolvimento dos desenhos de forma e armadura e devido ao responsável por tais desenhos (projetista BIM). O mapa de processos desenvolvido é exposto na Figura 10.

Figura 7. Exemplo de modelo BIM com armaduras
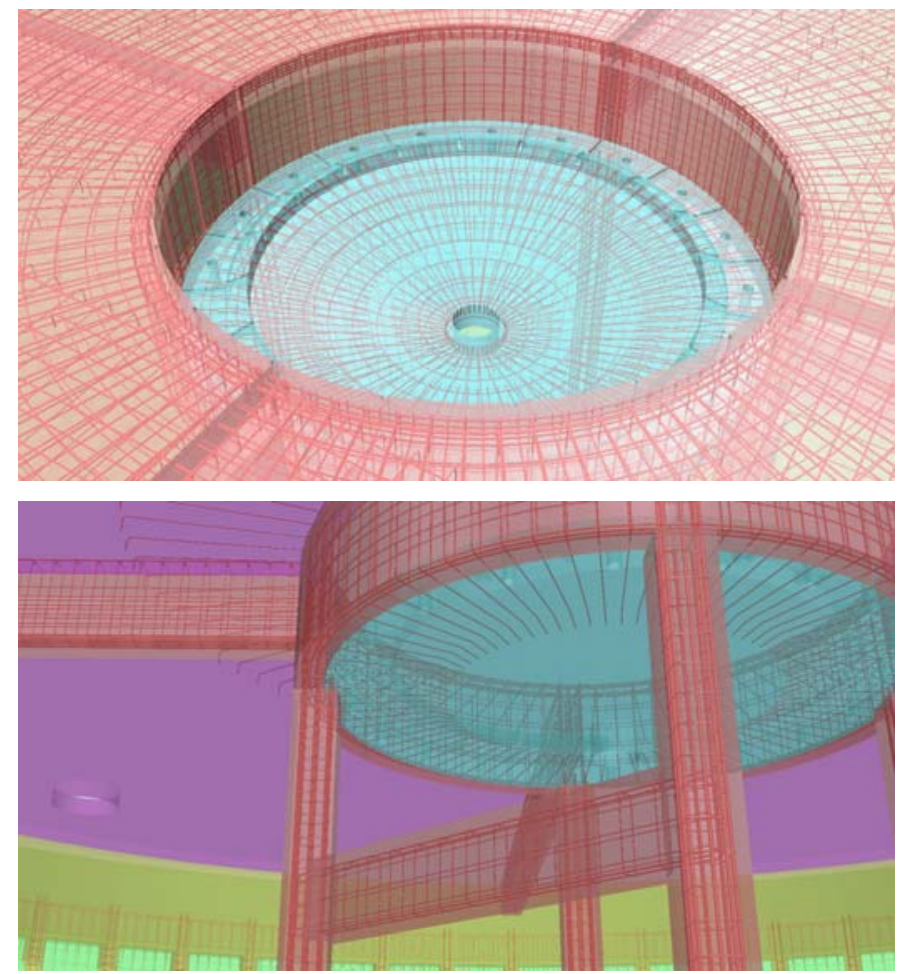

Fonte: Adaptada de Antunes (2014, p. 107)

Figura 8. Exemplo de parte de desenho de armaduras

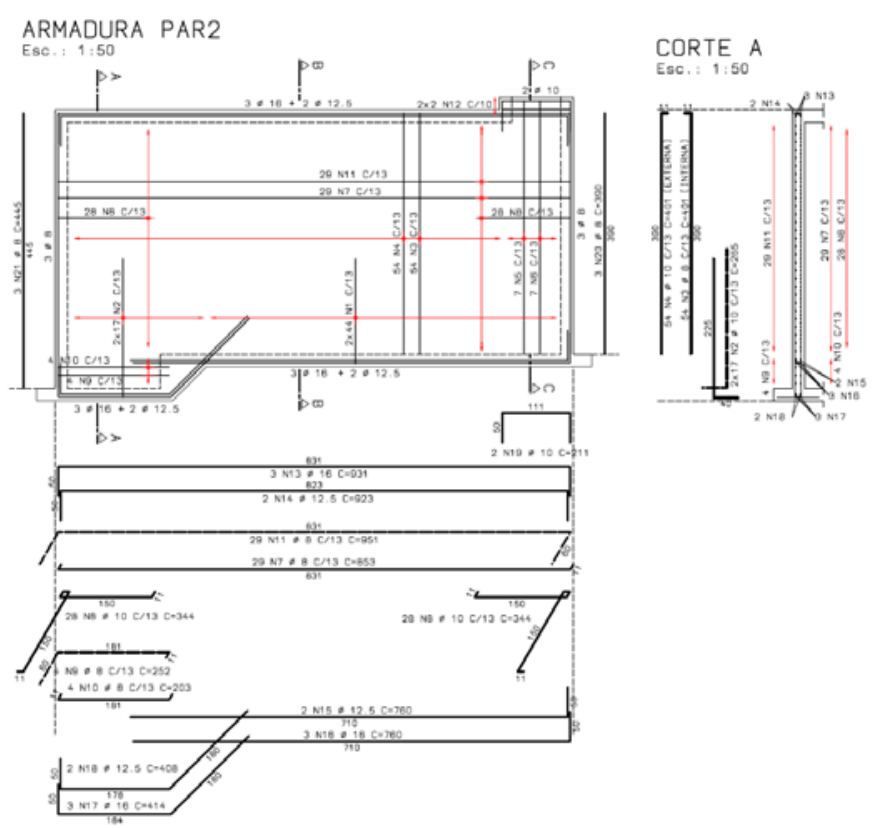

Fonte: Antunes (2014, p. 108) 
Figura 9. Mapa de processos do Fluxo A

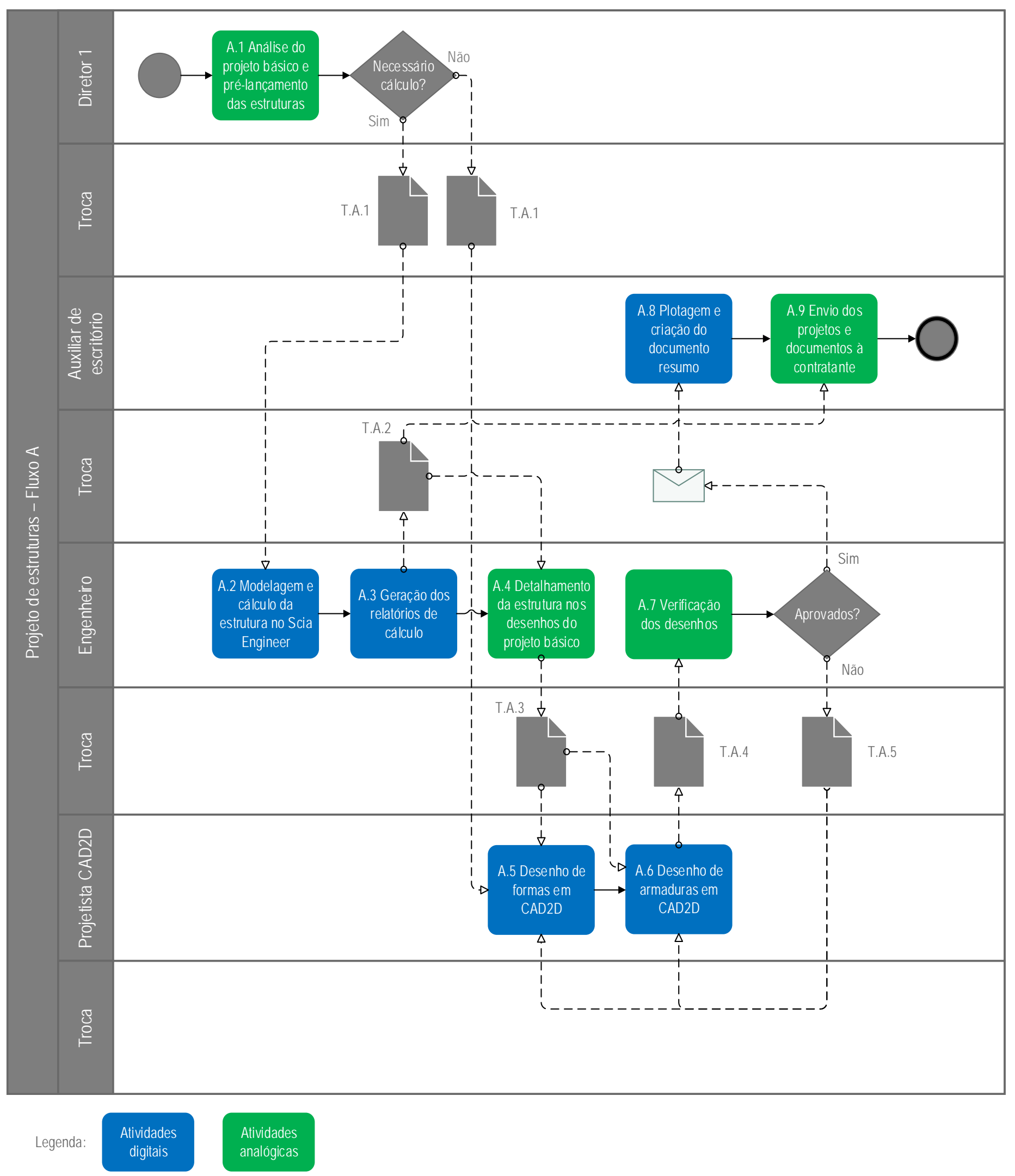

Fonte: Adaptada de Antunes (2014, p. 111) 
ANTUNES, Cristiano Eduardo; SCHEER, Sergio

Requisitos de informação e mapas do processo de projeto de estruturas em concreto armado: um estudo de caso utilizando a metodologia IDM

Figura 10. Mapa de processos do Fluxo B

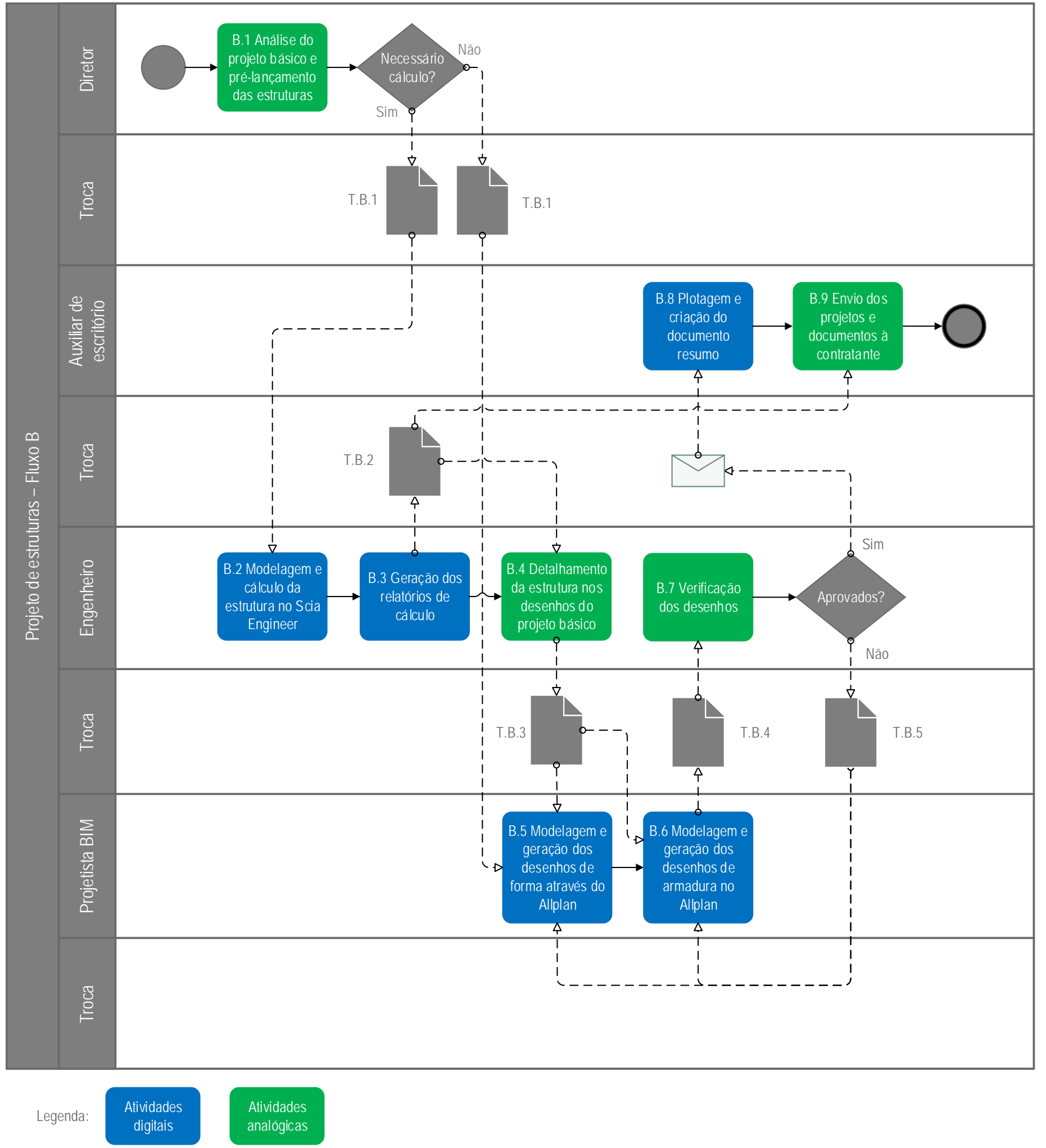

Fonte: Adaptada de Antunes (2014, p. 122)

O mapa se inicia com a análise do projeto básico e o prélançamento das estruturas por parte do Diretor. Quando as estruturas necessitam de cálculo estrutural, a tarefa seguinte é a B.2, caso contrário parte-se para B.5. A atividade B.2 envolve a modelagem e o cálculo da estrutura no Scia Engineer. Com a conclusão desta atividade, são gerados os relatórios de cálculo na tarefa B.3. O detalhamento da estrutura nos desenhos do projeto 
ANTUNES, Cristiano Eduardo; SCHEER, Sergio

Requisitos de informação e mapas do processo de projeto de estruturas em concreto armado: um estudo de caso utilizando a metodologia IDM

básico é a próxima etapa desenvolvida pelos engenheiros. Na sequência, desenvolve-se a modelagem da estrutura em BIM através do aplicativo Allplan e criam-se os desenhos de forma (B.5) e armaduras (B.6). O responsável por esta etapa é um projetista BIM.

Com os desenhos finalizados, os engenheiros os recebem para verificação (B.7). Caso sejam necessárias mudanças, é imprescindível retornar às atividades B.5 ou B.6. No momento em que alterações não são mais necessárias, a auxiliar de escritório recebe um aviso. Então é procedida a plotagem dos desenhos e a criação do documento resumo (B.8). Por fim, enviam-se ambos para a contratante. Apresenta-se, como exemplo, no Quadro 1 o Modelo de Troca T.B.2, constante do mapa de processos. Nele identificam-se cada uma das informações relevantes, bem como se elas são obrigatórias ou opcionais, e quais entidades IFC lhe dariam suporte.

Quadro 1. Modelo de troca T.B.2.

\begin{tabular}{|c|c|c|c|c|}
\hline Tipo & \multicolumn{4}{|l|}{ Modelo de Troca } \\
\hline Ident. & \multicolumn{4}{|l|}{ T.B.2 } \\
\hline Descrição & \multicolumn{4}{|c|}{$\begin{array}{l}\text { Modelo de Troca que contém as informações da modelagem e do dimensionamento estrutural desenvolvidos pelo aplicativo Scia } \\
\text { Engineer e que irão compor os relatórios de cálculo }\end{array}$} \\
\hline Tipo de informação & Informação requerida & $\begin{array}{l}\text { Obrigatória (0) } \\
\text { Opcional (OP) }\end{array}$ & Observações & Entidade IFC \\
\hline Modelo & Modelo BIM estrutural & 0 & $\begin{array}{l}\text { Representação do modelo estrutural } \\
\text { adotado }\end{array}$ & $\begin{array}{c}\text { IfcStructural } \\
\text { AnalysisModel }\end{array}$ \\
\hline \multirow{7}{*}{ Cargas } & Peso próprio & 0 & \multirow{7}{*}{$\begin{array}{l}\text { As cargas de empuxo de água, empuxo } \\
\text { de solo, subpressão e de monovias ou } \\
\text { guindastes podem ou não ocorrer, } \\
\text { dependendo da estrutura em questão }\end{array}$} & \multirow{4}{*}{$\begin{array}{l}\text { IfcStructural } \\
\text { Action }\end{array}$} \\
\hline & Sobrecarga permanente & 0 & & \\
\hline & Sobrecarga variável & 0 & & \\
\hline & Empuxo de água & $\mathrm{OP}$ & & \\
\hline & Empuxo de solo & $\mathrm{OP}$ & & \multirow{3}{*}{$\begin{array}{l}\text { IfcStructural } \\
\text { SurfaceAction }\end{array}$} \\
\hline & Subpressão & $\mathrm{OP}$ & & \\
\hline & Monovias, guindastes, etc. & $\mathrm{OP}$ & & \\
\hline Combinações & Combinações de cálculo & 0 & $\begin{array}{l}\text { Combinações das cargas utilizadas no } \\
\text { dimensionamento }\end{array}$ & $\begin{array}{l}\text { IfcStructural } \\
\text { LoadGroup }\end{array}$ \\
\hline \multirow[b]{2}{*}{ Solo } & Coeficiente de reação vertical & 0 & \multirow{2}{*}{$\begin{array}{l}\text { O coeficiente de reação vertical diz } \\
\text { respeito aos apoios considerados para a } \\
\text { estrutura }\end{array}$} & $\begin{array}{l}\text { IfcStructural } \\
\text { Connection }\end{array}$ \\
\hline & Tensões no solo de fundação & $\mathrm{O}$ & & $\begin{array}{l}\text { IfcStructural } \\
\text { Surface } \\
\text { Reaction } \\
\end{array}$ \\
\hline \multirow{4}{*}{ Esforços } & Momento fletor & 0 & \multirow{4}{*}{$\begin{array}{l}\text { Esforços internos atuantes em vigas, } \\
\text { pilares, lajes e paredes }\end{array}$} & \multirow{4}{*}{$\begin{array}{l}\text { IfcStructural } \\
\text { Reaction } \\
\text { IfcStructural } \\
\text { Surface } \\
\text { Reaction }\end{array}$} \\
\hline & Esforço cortante & 0 & & \\
\hline & Esforço normal & 0 & & \\
\hline & Torção & $\mathrm{OP}$ & & \\
\hline Armadura & Área de aço calculada & 0 & $\begin{array}{l}\text { Armadura calculada para cada elemento } \\
\text { estrutural pelo Scia Engineer }\end{array}$ & $\begin{array}{l}\text { IfcStructural } \\
\text { ResultGroup }\end{array}$ \\
\hline
\end{tabular}

Fonte: Os autores

Fluxo C

No Fluxo C, os desenhos de forma e armadura são desenvolvidos pelo próprio engenheiro que calculou a estrutura, através do aplicativo Allplan Engineering. $\mathrm{O}$ mapa de processos desenvolvido é representado na Figura 11.

\section{Observações a respeito dos fluxos}

A primeira observação a ser feita é que a simples utilização de aplicativos BIM não faz com que o processo de projeto seja condizente com o que propõe a Modelagem da Informação da Construção. Ainda que o uso de sistemas BIM possa facilitar e agilizar algumas atividades particulares, o total proveito dessa tecnologia só será obtido quando todos os envolvidos no processo trabalharem de forma integrada. 
Figura 11. Mapa de processos do Fluxo C

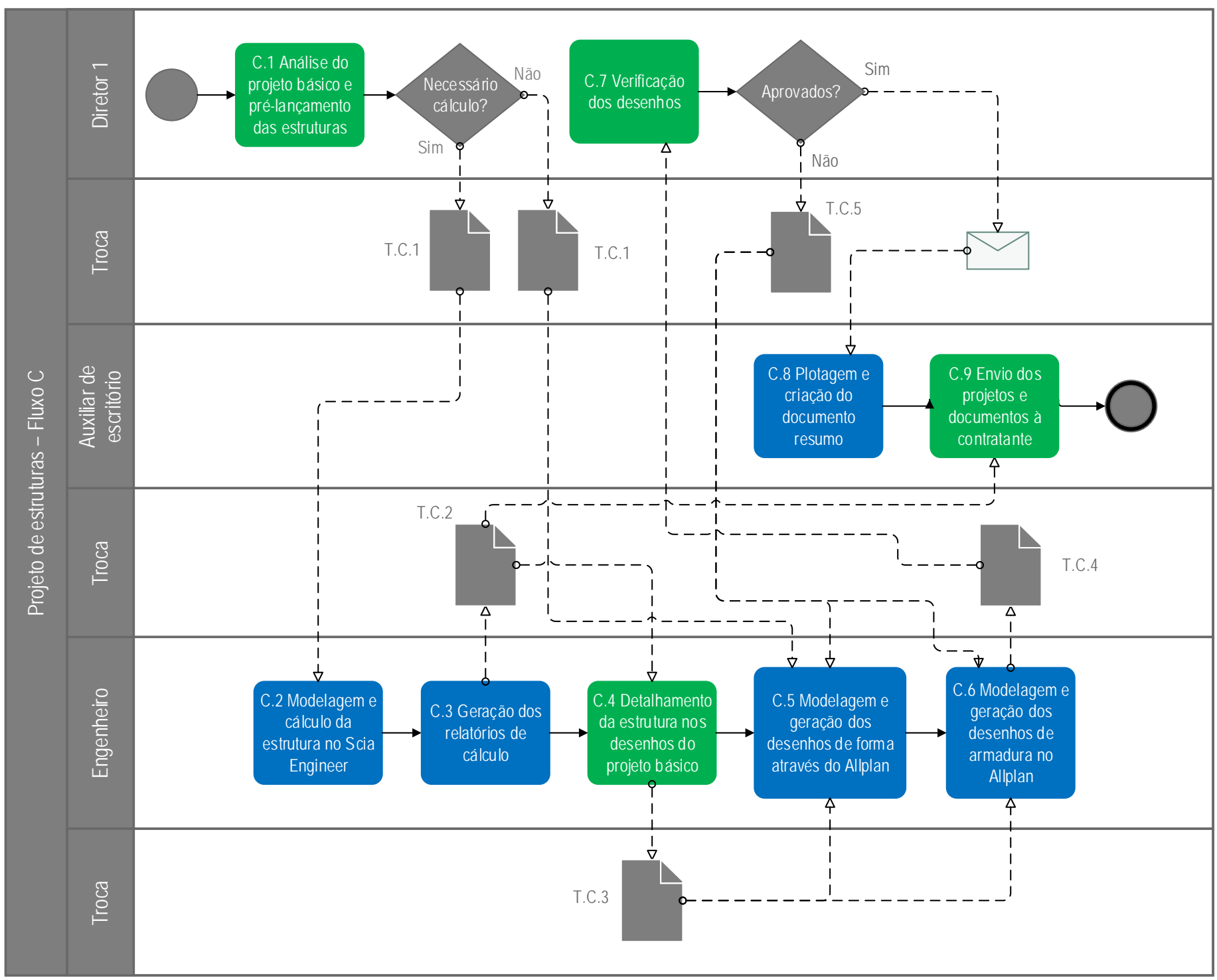

\section{Legenda: Atividades $\quad$ Atividades \\ digitais analógicas}

Fonte: Adaptada de Antunes (2014, p. 124)

Isso pode ser percebido no início dos três fluxos aqui apresentados. O projeto básico de engenharia é sempre recebido em formato $\mathrm{CAD} 2 \mathrm{D}$. Tal fato traz consigo todas as deficiências relacionadas à essa metodologia. Em se tratando do projeto estrutural, as principais dificuldades decorrentes de um projeto básico desta sorte são as omissões, insuficiências e conflitos de informações geométricas e físicas (especificações de materiais, entre outros). Ademais, um projeto básico em CAD 2D faz com que todas as atividades subsequentes devam passar pelos processos de abstração dos desenhos e "criação mental” da estrutura, além da laboriosa reinserção de dados.
Pode-se notar, ainda, através dos fluxos B e C, que os modelos BIM criados são utilizados apenas para o desempenho de algumas atividades específicas dentro da própria empresa. Tais modelos não são compartilhados com os demais envolvidos no empreendimento, como a contratante, o construtor, o responsável pelo projeto básico, etc. Destarte, os modelos têm a simples função de gerar os desenhos de forma e armadura, e não criar uma representação digital da obra real, como propõe o BIM.

A forma como a informação é passada do Diretor para os engenheiros ou para os projetistas, assim como a maneira que o detalhamento da estrutura é transmitido do engenheiro para os projetistas, também merece destaque. Anotações e desenhos sobre as folhas do projeto básico 
podem demandar um longo período de tempo. Além disso, o conteúdo das anotações e dos desenhos de detalhamento torna-se fragmentado. Tal conteúdo poderia ser disponibilizado em formato digital se, nessa etapa, já existisse um modelo BIM para representar a estrutura.

Percebe-se na descrição dos fluxos B e C que ao longo do processo são criados dois modelos BIM: um no Scia Engineer, com intuito de análise estrutural, e outro no Allplan, com intuito de geração dos desenhos de forma e armadura. Como relatado, nota-se que o modelo BIM estrutural é dotado de certas características próprias, que servem única e exclusivamente para a análise estrutural. Similarmente, o modelo BIM desenvolvido no Allplan, que visa a criação dos desenhos de forma e armadura, também possui atributos próprios.

É plausível, no entanto, fazer com que esses dois modelos se relacionem. Pode-se criar um modelo BIM estrutural no Scia Engineer e, após o cálculo e análise (atividades B.2 e B.3 do Fluxo B), exportá-lo ao Allplan através do formato IFC (para desenvolver as atividades B.5 e B.6), eliminando-se à etapa de detalhamento manual da estrutura. A maior dificuldade percebida neste procedimento foram as diferenças que existem entre o modelo que se presta à análise estrutural e o que serve aos desenhos de forma e armadura. Deste modo, diversas alterações são necessárias após o modelo ter sido transferido de um aplicativo para o outro.

Prosseguindo, devido ao fato de as estruturas serem modeladas uma a uma, não se tem uma visão global do empreendimento. Isso é percebido na criação do documento resumo pela auxiliar de escritório. Neste documento, são apresentados os resumos de volume de concreto, área de formas e peso de armaduras para toda a obra. Estes dados são obtidos através da observação dos desenhos de forma e armadura criados pelos projetistas ou pelos engenheiros. Se, por outro lado, existisse um modelo único para todo o empreendimento, as informações necessárias para o documento resumo seriam obtidas automaticamente.

\section{Fluxo Proposto}

Com base no estudo de caso, buscou-se propor um fluxo que otimizaria o processo de projeto de estruturas de concreto, maximizando as possibilidades proporcionadas pelo BIM e pelo IFC no tocante à interoperabilidade. Isto é, procurou-se reduzir o número de tarefas analógicas e propor trocas de informações que podem ser realizadas através do padrão IFC. Este fluxo é apresentado na Figura 12.

A atividade que dá início ao fluxo é a P.1, análise do projeto básico e pré-lançamento das estruturas, similar à atividade B.1, apresentada anteriormente. Esta atividade, desenvolvida pelo Diretor, foi mantida no fluxo proposto pois ela visa encaminhar os projetos básicos para os engenheiros ou enviar os projetos básicos com anotações de detalhamento para os projetistas BIM (T.P.1). A segunda atividade do fluxo é o desenvolvimento de um modelo BIM estrutural e cálculo da estrutura no Scia Engineer, idêntica à atividade B.2. De forma semelhante, a tarefa seguinte, geração dos relatórios de cálculo, é similar à B.3. A atividade que dá sequência ao fluxo é a P.4, criação do modelo BIM preliminar no Allplan e detalhamento da estrutura. Esta tarefa visa a criação de um modelo BIM a partir do modelo estrutural, desenvolvido no Scia Engineer. Para isso, o requisito de troca T.P.3 constitui-se na exportação, através do formato IFC, do modelo desenvolvido na tarefa P.2.

Uma vez no Allplan, o engenheiro desenvolveria o detalhamento da estrutura, com suas devidas espessuras e seções transversais, incluindo a modelagem das armaduras principais, tarefa que antes era feita na forma de desenhos sobre o projeto básico. Deste modo, a informação não se torna fragmentada, mas mantém-se intrínseca ao modelo. Prosseguindo, o projetista BIM receberia este mesmo modelo para fazer os refinamentos necessários, englobando todos os detalhes que não são de interesse para o modelo BIM estrutural, mas que demonstram-se necessários nesta etapa. Além do refinamento, o projetista faria a geração dos desenhos de forma e de armaduras da estrutura.

O restante do processo continua o mesmo apresentado no Fluxo B. Pode-se, no entanto, fazer com que todos os modelos gerados separadamente na etapa P.4 sejam integrados em um só na tarefa P.5. Desta forma, o documento resumo dos materiais poderia ser gerado automaticamente.

\section{Análise do Fluxo Proposto}

O fluxo proposto neste trabalho fez com que a atividade de detalhamento da estrutura, executada pelo engenheiro, passasse a ser realizada em ambiente digital, através do aplicativo Allplan. Anteriormente, esta atividade era feita analogicamente, consumindo grande tempo e fazendo com que a informação se mantivesse fora do modelo. Acredita-se que o tempo necessário para a realização dessa atividade em ambiente digital seja menor. Além disso, a criação do modelo preliminar pelo engenheiro elimina a necessidade de o projetista desempenhar esta tarefa na sequência. Em contrapartida, ressalta-se que é necessário que o engenheiro possua conhecimento no aplicativo, o que pode requerer investimento em treinamento. 
Figura 12. Mapa de processos do Fluxo Proposto

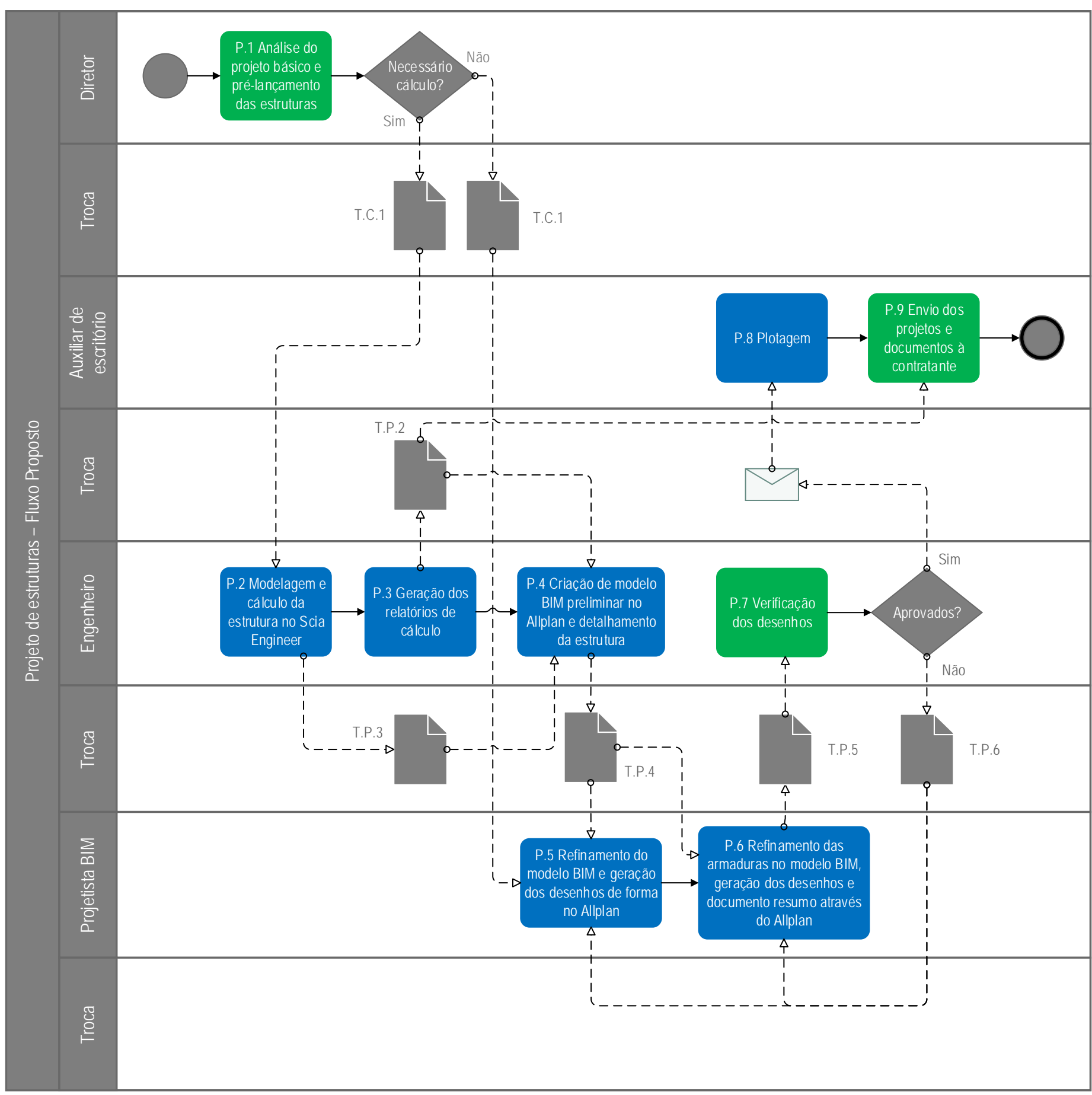

Legenda:

Fonte: Adaptada de Antunes (2014, p. 128)

O projetista, por sua vez, ao invés de criar o modelo BIM, irá apenas refiná-lo, modificando e inserindo informações com base no modelo preliminar. A auxiliar de escritório não precisará confeccionar o documento resumo de materiais, recaindo essa atividade ao próprio projetista, que a realizará também em ambiente digital.
A eficácia das novas trocas de dados criadas (T.P.3 e T.P.4) através do formato IFC deve ser verificada com critério. Testes iniciais, com a exportação direta de um software a outro, revelam que o intercâmbio de dados é realizado corretamente. 


\section{Conclusão}

Este trabalho visou o estudo do processo de projeto de estruturas de concreto através de sistemas BIM, utilizando a metodologia IDM. Destacam-se como relevantes no cenário internacional as pesquisas de Sacks et al. (2010), Mondrup, Karlshoj e Vestergaard (2012), Berard e Karlshoj (2012), Aram, Eastman e Sacks (2013) e Nawari (2012). Percebe-se que o presente trabalho é dotado de caráter original, posto que avalia uma prática do cenário brasileiro da indústria da construção.

$\mathrm{O}$ relato do estudo de caso descreve minuciosamente a empresa onde o estudo foi desenvolvido, bem como o processo de projeto da mesma. Com base no relato foi possível a criação de mapas de processo e Modelos de Troca, seguindo os padrões propostos pela metodologia IDM. Desta maneira, foram estabelecidas quais informações são necessárias para a perfeita execução de cada uma das tarefas que compõe um projeto de estruturas. Tais classes de informação foram identificadas também no padrão IFC, esclarecendo, para os desenvolvedores, os processos estudados.
Finalmente, propôs-se um fluxo no intuito de otimizar o processo de projeto de estruturas de concreto armado na empresa. Tal fluxo foi apresentado também nos padrões do IDM, constando de mapa de processo e Modelos de Troca, e reduziu o número de tarefas analógicas, propondo novas formas de troca de informações, o que pode esclarecer os processos utilizados pelos usuários finais.

Atingidos os objetivos de mapear os processos e requisitos de informação e de propor um processo de projeto de estruturas de concreto através de sistemas BIM, pode-se concluir que o IDM foi uma ferramenta valiosa no decorrer do estudo. Os mapas de processo e os Modelos de Troca criados podem também vir a dar suporte ao desenvolvimento de aplicativos BIM que visem atender esse nicho de projetos, bem como acelerar a adoção de BIM no mercado.

Como sugestão de trabalho futuro, pode-se testar o fluxo aqui proposto em uma empresa de projetos de estruturas, procurando verificar a eficiência do mesmo em relação às práticas comumente adotadas.

\section{Referências}

ANDRADE, M. L. V. X.; RUSCHEL, R. C. Interoperabilidade de aplicativos BIM usados em arquitetura por meio do formato IFC, Gestão \& tecnologia de projetos, v. 4, n. 2, 2009.

ANTUNES, C. E. Mapeamento de processos e determinação de requisitos de informação em projetos de estruturas em concreto armado para obras de saneamento através de sistemas BIM: estudo de caso utilizando a metodologia IDM. Dissertação (Mestrado em Engenharia de Construção Civil), Universidade Federal do Paraná, Curitiba, 2014.

ARAM, S.; EASTMAN, C.; SACKS, R. Requirements for BIM platforms in the concrete reinforcement supply chain. Automation in Construction, v. 35, p. 1-17, 2013.

AZHAR, S. Building Information Modeling (BIM): Trends, Benefits, Risks, and Challenges for the AEC Industry. Leadership and Management in Engineering, v. 11, n. 3, 2011.

ASSOCIAÇÃO BRASILEIRA DE NORMAS TÉCNICAS. NBR 6118: Projeto de estruturas de concreto - Procedimento. Rio de Janeiro, 2007.

BERARD, O.; KARLSHOJ, J. Information Delivery Manuals to integrate building product information into design. Journal of Information Technology in Construction, v. 17, 2012.

BUILDINGSMART. Industry Foundation Classes: IFC4 Release Candidate 4. 2012. Disponível em: <http://www.BuildingSMART-tech.org/ifc/IFC2x4/rc4/html/index.htm>. Acesso em: 04/02/2013.

. Information Delivery Manual: Guide to Components and Development Methods. 2010. Disponível em: <http://iug.BuildingSMART.org/idms/development/IDMC_004_1_2.pdf>. Acesso em: 21/01/2013.

EASTMAN, C.; TEICHOLZ, P.; SACKS, R.; LISTON, K. BIM Handbook: A Guide to Building Information Modeling for Owners, Managers, Designers, Engineers, and Contractors. 2.ed. New Jersey: Wiley, 2008. 
ANTUNES, Cristiano Eduardo; SCHEER, Sergio

Requisitos de informação e mapas do processo de projeto de estruturas em concreto armado: um estudo de caso utilizando a metodologia IDM

EASTMAN, C.; JEONG, Y. S.; SACKS, R.; KANER, I. Exchange Model and Exchange Object Concepts for Implementation of National BIM Standards. Journal of Computing in Civil Engineering, v. 24, n. 1, p. 25-34, 2010.

FERREIRA, S. L. Proposta de ampliação do modelo IFC com a contribuição do IES LM-63: a luminária no ciclo de vida da edificação. Tese (Doutorado em Engenharia de Construção Civil e Urbana) - Escola Politécnica, Universidade de São Paulo, São Paulo, 2005. Disponível em: <http://www.teses.usp.br/teses/disponiveis/3/3146/tde-23052006-182302/>. Acesso em: 30/09/2014.

LAAKSO, M.; KIVINIEMI, A. The IFC standard - a review of history, development, and standardization. Journal of Information Technology in Construction, v. 17, p. 134-161, 2012.

MONDRUP, T. F.; KARLSHOJ, J.; VESTERGAARD, F. Information delivery manuals to facilitate IT supported energy analysis. In: CIB W078 2012 CONFERENCE, Proceedings... Beirute, 2012.

NAWARI, N. O. BIM Standard in the Structural Domain. Journal of Civil Engineering and Science, v. 01, n. $02,2012$.

NBIMS - National Building Information Modeling Standard. Overview, Principles and Methodologies, Version 1.0 — Part 1 , 2007. Disponível em: <http://www.wbdg.org/pdfs/NBIMSv1_p1.pdf>. Acesso em: 07/04/2012.

ROBSON, C. Real world research: a resource for social scientists and practitioner - researchers. 2nd ed. Blackwell Publishing, 2002.

SACKS, R.; KANER, I.; EASTMAN, C. M.; JEONG, Y. S. The Rosewood experiment - Building information modeling and interoperability for architectural precast facades. Automation in Construction, v. 19, n. 4, p. 419-432, 2010.

SANEPAR. Perfil, 2014. Disponível em: <http://site.sanepar.com.br/a-sanepar/perfil>. Acesso em: 10/01/2014.

YIN, R. K. Estudo de caso: planejamento e métodos. 2.ed. Porto Alegre: Bookman, 2001. 